\title{
LA CRISIS COMO OPORTUNIDAD. UNA APROXIMACIÓN A PARTIR DEL LEVANTAMIENTO DE LOS LIBRES DEL SUR (1837-1842)
}

\author{
The crisis as opportunity. An approximation from the Uprising of the Frees of \\ the South (1838-1841)
}

Carolina Germinario*

https://orcid.org/0000-0003-3412-3466

\section{Resumen}

El presente trabajo es un abordaje al Levantamiento de los Libres del Sur (1839) a partir de la crisis de los años 1838-1841. En esta coyuntura, una serie de conflictos regionales y locales, de índole económica, fiscal y política, habilitaron la configuración de disidencias contra el Gobernador de la Provincia de Buenos Aires, Juan Manuel de Rosas. El objetivo del trabajo es presentar cuáles fueron los motivos que permiten caracterizar estos años como críticos y cuál fue su impacto en la escala rioplatense y, específicamente, en la escala micro de los partidos de Dolores y Monsalvo, centros del Levantamiento. A partir de recuperar los aportes de la historia política y la historia rural rioplatense, construimos la problematización de la sublevación y revisamos las condiciones sociales, demográficas y económicas del espacio geográfico, entre mediados del siglo XVIII y 1839. A su vez, realizamos un análisis crítico de fuentes (prensa, ensayos históricos y documentos oficiales) que nos permite complejizar la lectura de la crisis a partir de las voces de los actores.

$$
<\text { Crisis }><\text { Rosas }><\text { Buenos Aires }><\text { Levantamiento }>
$$

\begin{abstract}
This paper approaches the uprising of the of the Libres del Sur (1839) from the crisis of the years 1838-1841. During this period, a series of regional and local economic, financial and political conflicts enabled the configuration of dissidences against the Governor of the Buenos Aires Province, Juan Manuel de Rosas. This work aims to present the causes that characterize these years as critics, and its impact on the rioplatense scale and specifically on a micro scale at the jurisdiction of Dolores and Monsalvo, centers of the uprising which were the causes that allow us to characterize these years as critics and which was it impact in the rioplatense scale and specifically in a micro scale of the jurisdiction of Dolores and Monsalvo, centers of the uprising. From contributions of the political and rural history of the Río de la Plata, we analyze the uprising and examine the social, demographic and economic conditions of the geographic space between mid-18th century and 1839. In addition, we analyze critically primary sources (press, historical essays, and official documents) to provide a complex reading of the crisis from the agents' voices.
\end{abstract}

$<$ Crisis $><$ Rosas $><$ Buenos Aires $><$ Uprising $>$

Recibido: 03/02/2021 // Aceptado: 19/07/2021

* Centro de Estudios Históricos, Facultad de Humanidades, Universidad Nacional de Mar del Plata (UNMDP), Mar del Plata, Argentina, germinariocarolina@gmail.com 
Germinario. La crisis como oportunidad. Una aproximación a partir del Levantamiento de los Libres del Sur...

\section{Introducción: el marco historiográfico, problemas y preguntas}

Entre los años 1837 y 1842 la Provincia de Buenos Aires, bajo el mando de Juan Manuel de Rosas, experimentó una crisis muy profunda que alteró, tanto en lo político como en lo económico, las estrategias de alianzas y negociación del gobernador. Los objetivos de este trabajo son, en primer lugar, revisar el conjunto de problemas que permiten caracterizar la coyuntura como crítica; en segundo lugar, proponer una explicación integral de la crisis en una escala de análisis específica: los partidos de Dolores y Monsalvo en el sudeste de la provincia. Este espacio fue el epicentro del Levantamiento de los Libres del Sur en el año 1839. Nos interesa mostrar aquí que los años de crisis fueron entendidos como una oportunidad por los detractores de Rosas para manifestar su disidencia. La crisis posibilitó la configuración de redes de relaciones preexistentes que culminaron en el Levantamiento. A su vez, estos vínculos excedían al entorno rural entrelazándose con la Ciudad de Buenos Aires y con un espacio rioplatense de mayor alcance. ${ }^{1}$

El corpus bibliográfico que ha estudiado las décadas que van desde fines del siglo XVIII a mediados del siglo XIX, en el espacio americano y rioplatense, en particular, es extenso y se encuentra muy consolidado. El problema general, de orden político, que recorre este periodo lo constituyen las disputas por la construcción de un nuevo orden, ${ }^{2}$ iniciado, en parte, por las reformas borbónicas y catalizado por la ruptura revolucionaria y las Guerras de Independencia. A su vez, el espacio rioplatense estaba atravesado por transformaciones productivas y económicas que se encaminaban hacia una reorientación atlántica. A continuación, presentamos los aportes centrales de las diversas líneas historiográficas que han abordado, y continúan trabajando, ambos grupos de problemas y que ponemos en juego para elaborar este trabajo. Nos enfocamos en las producciones que, en las últimas tres décadas, permiten nuevas lecturas sobre la acción y participación política de los actores en relación con sus prácticas sociales y económicas.

Estas investigaciones se pueden ordenar, de manera analítica, en aquellas que se insertan en la historia política y en las que provienen de la historia rural rioplatense. Estas dos grandes líneas historiográficas están hoy un poco desdibujadas debido a la superposición de temas, problemas y enfoques. Para este trabajo, en particular, la historia política nos permite dimensionar las acciones de los actores en su contexto, partiendo de

\footnotetext{
1 Este trabajo es un extracto de la tesina presentada para la Licenciatura en Historia en la Universidad Nacional de Mar del Plata, por lo que los objetivos planteados se enmarcan en el objetivo general del proyecto de investigación actual.

2 Al referirnos a la idea de orden, tanto político como social, nos basamos en la caracterización que elabora Moutoukias para la Monarquía Hispánica quien sostiene que "el orden político (y social) de la monarquía, que reposaba sobre una matriz de convenciones entendidas como reglas implícitas y naturalizadas. Reglas compartidas que permiten anticipar y descifrar el comportamiento de los otros, tan integradas que los actores no necesitan explicitarlas." (Moutoukias, 2017, p. 96). A su vez, el autor enuncia que dicho orden se basaba en el dispositivo institucional que tenía al Rey como eje ordenador y que, al desagregarse institucionalmente la Monarquía, a comienzos del siglo XIX, con la invasión napoleónica, la fragmentación territorial hundió a muchas regiones en la violencia y en la búsqueda de los mecanismos que permitieran sustituir el orden previo.
} 
la premisa de que la política no es una actividad exclusiva de las élites ni de los grupos dirigentes. ${ }^{3}$ A su vez, los escritos que se ocupan, desde un enfoque económico y social, pero también político, de cómo se dio el poblamiento de la campaña de Buenos Aires, en el largo período que va entre mediados y fines del siglo XVIII y el siglo XIX, nos permiten comprender que este espacio geográfico era, además de muy extenso, muy complejo en cuanto a su estructura poblacional y económico-social. La idea central es que la campaña era, hacia mediados del siglo XIX, un espacio muy dinámico, con zonas de antigua y de nueva ocupación (sur del Río Salado) que, con la atlantización de la economía, estaban experimentando un crecimiento vinculado a la exportación de derivados ganaderos. Esto no significaba que existían formas de usufructuar las tierras totalmente capitalistas, sino que convivían prácticas de subsistencia con las grandes y medianas explotaciones. ${ }^{4}$

Desde el diálogo entre ambas propuestas, se estudia hoy la figura de Juan Manuel de Rosas y su tiempo en el poder. A lo largo de su extensa gobernación, Rosas construyó diferentes formas de sostener su liderazgo político, vinculándose con la diversidad de actores que habitaban ciudad, campaña y el espacio regional. ${ }^{5}$ Las investigaciones sobre la coyuntura de crisis que aquí buscamos revisitar versan sobre los aspectos más socio-económicos y facciosos, en términos de unitarios y federales. El trabajo de Jorge Gelman, Rosas bajo fuego, es una síntesis muy actualizada del encuentro entre perspectivas historiográficas. Sin embargo, encontramos en este abordaje algunas vacancias que nos habilitan a elaborar nuevas preguntas. En primer lugar, queda velada la acción política del Levantamiento como una disidencia. Consideramos que al verla de esta manera podemos abonar a la complejidad y flexibilidad de las identidades y adscripciones políticas en el tiempo que nos ocupa. En segundo lugar, nos resulta interesante desentrañar cuáles fueron los vínculos entre el movimiento regional de Lavalle y la acción más local de los Libres, buscando comprender los puentes y el diálogo entre ambos movimientos, así como sus particularidades. En esta línea, y, en tercer lugar, revalorizar la dimensión espacial del Levantamiento y cómo fue puesta en juego por los actores nos lleva a preguntarnos sobre la territorialidad del poder y las dinámicas locales en la campaña al sur del Salado.

\footnotetext{
${ }^{3}$ Sobre la nueva historia política se pueden encontrar reflexiones muy interesantes en el libro Palacios, G. (Ed.). (2007). Ensayos sobre la nueva historia política de América Latina: Siglo XIX(1.a ed.). El Colegio de México. Especialmente el artículo de Hilda Sábato, titulado: "La política argentina en el siglo XIX: notas sobre una historia renovada" (pp.83-94).

${ }^{4}$ Un balance completo y detallado del desarrollo de la historia rural rioplatense en Santilli, D. (2017). La saga continúa: La historiografía rural de la campaña de Buenos Aires en la primera mitad del siglo XIX. En S. Bandieri \& S. Fernandez, La Historia Argentina en perspectiva local y regional. Nuevas miradas para viejos problemas, 1, Buenos Aires: Teseo. pp. 279-317.

${ }^{5}$ El trabajo de síntesis más completo hasta el momento, y que presenta la diversidad de abordajes sobre Juan Manuel de Rosas es la biografía publicada en el año 2015 por Jorge Gelman y Raúl Fradkin: Fradkin, R., \& Gelman, J. (2015). Juan Manuel de Rosas: La construcción de un liderazgo político. Buenos Aires: Edhasa.
} 
Germinario. La crisis como oportunidad. Una aproximación a partir del Levantamiento de los Libres del Sur...

Este trabajo se organiza en cuatro apartados ${ }^{6}$. En el primero, presentamos un análisis social, demográfico y económico de las jurisdicciones de Dolores y Monsalvo hacia el año 1839, a partir de la bibliografía específica, que nos habilita a reflexionar sobre el impacto de las reformas económicas tomadas en el contexto de la crisis. En el segundo, realizamos la revisión de la coyuntura crítica a nivel regional articulando los aspectos económicos y políticos. En el tercero, desarrollamos, a través de fuentes primarias y secundarias, nuestra explicación integral de la crisis en la campaña. Por último, desplegamos las conclusiones a las que hemos llegado hasta el momento en nuestra investigación.

\section{El sudeste de la campaña hacia 1839: Dolores y Monsalvo}

Hacia fines del siglo XVIII, la campaña de Buenos Aires estaba constituida por el entorno rural de la ciudad. Para 1839, este espacio había experimentado una expansión considerable, incorporando miles de hectáreas bajo su órbita. Las tierras al sud del Río Salado tenían, por esta fecha, una vitalidad económica estrechamente asociada a la exportación de derivados ganaderos. Para comprender cómo la campaña del sudeste se convirtió en una de las zonas con mayor riqueza relativa del período es necesario remontarnos a los comienzos del siglo XVIII. El Litoral Rioplatense y la campaña de Buenos Aires experimentaron, durante este siglo, un despegue económico y socio-demográfico. La estructuración de un espacio económico rioplatense, ya desde comienzos de siglo, estuvo vinculada a un complejo productivo de base agropecuaria y una muy activa área de servicios, estimulados por el comercio y la Corona (Jumar, 2018, p. 35). Esto significó un crecimiento poblacional, nutrido por migraciones internas que tuvieron como destino las ciudades de Buenos Aires y Montevideo y, luego, la campaña que comenzó a expandirse territorialmente.

En la segunda mitad del siglo XVIII, con el reformismo borbónico, el área aledaña a Buenos Aires se posicionó como centro de abastecimiento para los requerimientos urbanos y también como productor para la incipiente exportación portuaria de cueros y derivados. ${ }^{7}$ La expansión territorial impuso el refuerzo de la frontera sur con el Río Salado hacia fines del siglo XVIII mediante el establecimiento de fortines (Ciliberto \& Rosas Principi, 2014, p. 226). Los cambios políticos y la ruptura del vínculo colonial supusieron, a su vez, una aceleración de los procesos de reorientación atlántica. Entre 1808 y 1820 la crisis monárquica, la Revolución y las Guerras de Independencia

\footnotetext{
${ }^{6}$ Agradezco especialmente a los/as revisores anónimos de la revista y a los editores por los aportes y comentarios realizados que me permitieron reelaborar y ampliar el artículo.

7 Zacarías Moutoukias ha acuñado para el período 1760-1820 la propuesta de "globalización arcaica". Esta idea sostiene que las dinámicas de globalización, mediación y circulación producto de los enfrentamientos entre los imperios durante el siglo XVIII tuvieron un efecto importante en el orden político e institucional y su posterior fractura. El autor ejemplifica la propuesta de "globalización arcaica" con la experiencia porteña de fines del siglo XVIII, en donde podemos ver que Buenos Aires y el Río de la Plata estaban, más allá de los aspectos económicos, atravesados por un orden y una dimensión política de alcance global (Moutoukias, 2018, p. 177).
} 
perturbaron el cuadro de situación. La desintegración del eje económico Potosí-Buenos Aires trastocó la economía del conjunto de regiones que integraban el Virreinato.

Las secciones de Dolores y Monsalvo abarcaban toda la región al sur y el este del Salado, extendiéndose sobre la costa marítima (Figura 1). ${ }^{8}$ Monsalvo comprendía alrededor de $21000 \mathrm{~km}^{2}$ con una población estimada en 3048 en 1838 . Mientras que Dolores $8900 \mathrm{~km}^{2}$ con 2803 habitantes hacia 1838. En ambos la ganadería era la actividad principal (Gelman \& Santilli, 2004, p. 249). El Curato de Nuestra Señora de Dolores y la Comandancia militar y política de las Islas del Tordillo, establecidos hacia mediados de la década revolucionaria, fueron atacados por diversos malones indígenas sucesivos en 1821, 1823 y 1826. Esto llevó a la refundación del pueblo en 1826, con su traza definitiva. A su vez, entre 1821 y 1825 quedó integrado en el Partido de Monsalvo, por lo que tenían un Juez de Paz para las dos secciones. Finalmente, en 1831 cada partido comenzó a tener su propio Juez (Mascioli, 2004, pp. 44-52, 2004).

Figura 1. Detalle de la ubicación aproximada de los partidos de Dolores, Monsalvo y Tandil hacia 1839

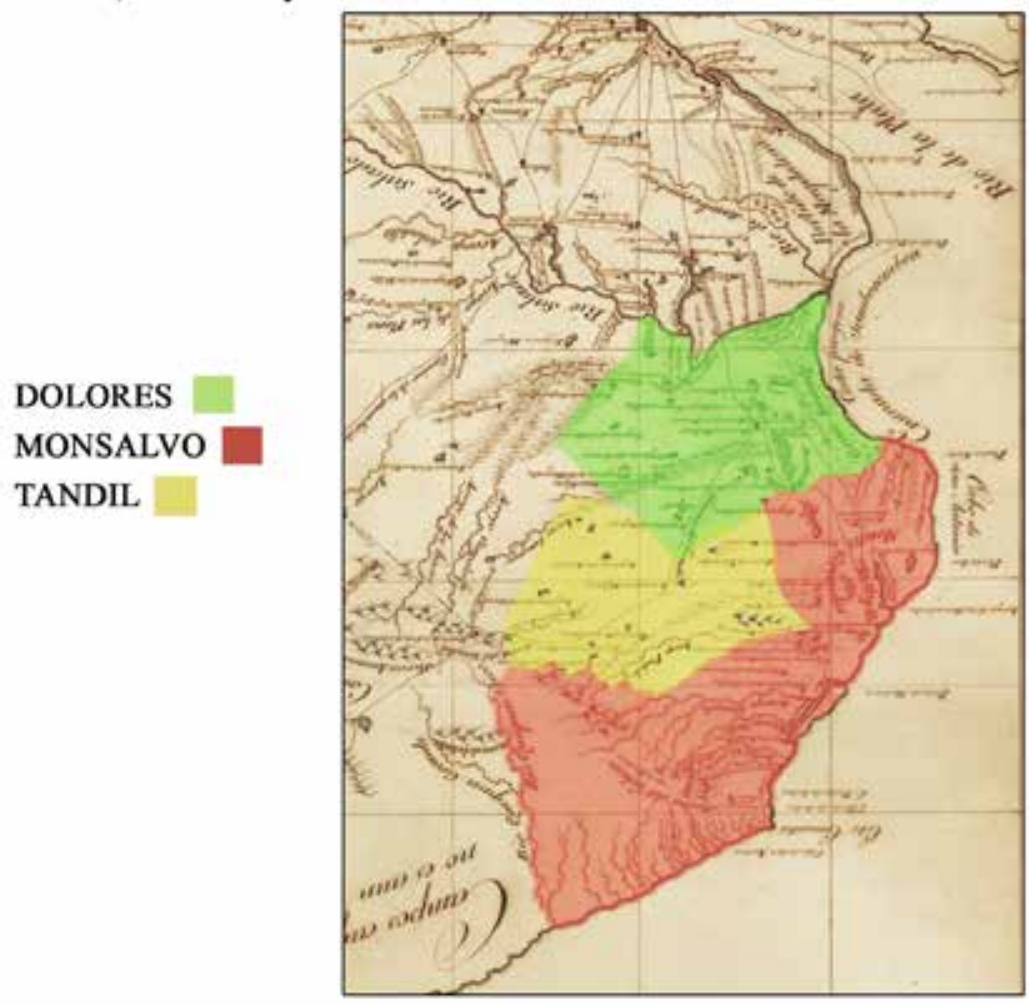

Fuente: ELaboración propia sobre la Carta Geográfica de la Provincia de Buenos Aires realizada en 1829 (AHGyC) y el Registro Oficial de Gobierno de la Provincia de 1839.

\footnotetext{
${ }^{8}$ Las descripciones del mapa están al revés ya que la Carta Geográfica de 1829 realizada por el Departamento Topográfico tenía el norte invertido (como era usual en la época). Para el entendimiento y la coherencia con los demás mapas del trabajo invertimos la imagen.
} 
Germinario. La crisis como oportunidad. Una aproximación a partir del Levantamiento de los Libres del Sur...

La gran extensión del partido de Monsalvo, no sólo lo posicionaba como el de mayor tamaño de toda la Provincia, sino que, además, era el más rico para 1839. Esta última característica se expresa a partir del análisis del impuesto a la Contribución Directa ${ }^{9}$ en dicho año. Monsalvo acumulaba el $14,5 \%$ del total de la riqueza de la campaña, especialmente en lo que al ganado refiere. El partido de Dolores no se quedaba atrás en cuanto a riquezas de ganado, estando entre los diez primeros, pero se destacaba, sobre todo, en el rubro relativo al giro comercial (Gelman \& Santilli, 2004, pp. 249-254).

A partir del análisis de la bibliografía de corte económico-productivo podemos afirmar que ambas secciones tenían un marcado cariz ganadero. Lo que se vincula con el contexto referido previamente de expansión de la frontera y la exportación de productos pecuarios. Sin embargo, Dolores y Monsalvo, presentaban hacia el período 1838-1840 algunas diferencias. Al tomar como variable la población y la extensión, se evidencia que la sección de Monsalvo poseía una densidad de población de 0,14 hab/ $\mathrm{km}^{2}$, mientras que en Dolores era $0,31 \mathrm{hab} / \mathrm{km}^{2}$. En relación con esto cobra sentido la importancia del comercio en la economía de esta sección, sobre todo por la existencia del pueblo, sumado a su mayor cercanía con Buenos Aires y otros pueblos importantes de la región como Chascomús.

Otro elemento socio-económico importante a destacar tiene que ver con la distribución de la tierra en ambas secciones. Para el caso de Dolores, Alejandra Mascioli concluye que para 1840 abundan los individuos que controlan extensiones de tierra reducidas, mientras que son pocos aquellos que poseen grandes extensiones. ${ }^{10}$ Esta caracterización se transforma para la sección de Monsalvo en la que, según Jorge Gelman, abundan las grandes estancias ganaderas y es clara la ausencia de explotaciones agrícolas más vinculadas al autoabastecimiento (Gelman, 1996, p. 10). Un último comentario con respecto a las características sociodemográficas de las secciones estudiadas está vinculado a otra de las conclusiones de Mascioli. La autora sostiene que, a partir de la información brindada en el censo de 1836, la población del partido de Dolores estaba compuesta por individuos que están altamente vinculados entre sí. El 93\% tenía alguna relación consignada, ya sea familiar, laboral o de otro tipo. La densidad de esta red de relaciones es un elemento muy importante para comprender las prácticas propias de este espacio.

Por último, quisiéramos recuperar algunas de las ideas de Antonio Galarza sobre la desigualdad en Chascomús hacia 1839. El autor realiza un análisis comparativo entre 1814 y 1839, enfocándose en el comercio y realiza algunas conclusiones interesantes.

\footnotetext{
${ }^{9}$ El impuesto a la Contribución Directa fue creado en los años veinte y gravaba las riquezas según diferentes rubros (ganado, giro comercial, labranza y otros). El arancel aplicaba un porcentaje según el capital invertido en cada rubro. Con el pasar de los años los porcentajes se mantuvieron fijos y además la declaración de los bienes debía hacerla cada capitalista, con lo que la recaudación era baja. En 1839 se dispuso una modificación en la forma del cobro del impuesto, lo que desarrollaremos en el próximo apartado.

${ }^{10}$ En 1840, en el partido de Dolores el $71 \%$ de los individuos controla relativamente poca tierra, unidades de entre 0 y 8099 hectáreas, lo que corresponde al 22,4\% del total de tierras disponibles en la zona. Mientras que, en el mismo año, el $29 \%$ restante tiene el control del $77,6 \%$ de la tierra, con unidades de entre 8100 y 40500 hectáreas (Mascioli, 2004, p. 154).
} 
En primer lugar, detecta, al menos en ese rubro, una desigualdad creciente, aunque no abismal. Esto quiere decir que, entre quienes se dedicaban al comercio, los más ricos hacia 1814 lo eran aún más en 1839, mientras que quienes menos tenían no habían mejorado su condición, y en algunos casos había empeorado (Galarza, 2010, p. 38). El autor busca desandar el camino que sostiene que la causa principal del levantamiento es debido a los problemas causados por el bloqueo, con el fin de ensayar una respuesta más compleja. Para ello analiza un caso particular, que le permite justamente matizar este enfoque. Galarza encuentra que uno de los comerciantes más importantes de Chascomús, y participante de la sublevación, no solo no se vio perjudicado sino que pudo incrementar sus recursos hacia 1839 (Galarza, 2010, p. 41).

El Levantamiento de los Libres del Sur sucedió en una coyuntura de crisis para el gobierno. Quienes lideraron este movimiento sedicioso eran, en su mayoría, hombres considerados notables que contaban con un alto grado de inserción en la sociedad rural. ${ }^{11}$ Además, habían tenido o incluso tenían hasta el momento, participación en los elencos de los juzgados o en la estructura militar-miliciana de la Provincia. A continuación, explicamos cuáles son las características que permiten caracterizar los años 18381841 como críticos y cómo estos actores pertenecían y se integraban en una trama de relaciones que se activó en función de la crisis.

\section{La coyuntura de crisis en el marco del gobierno de Rosas}

La llegada al poder de Juan Manuel de Rosas estuvo marcada por alzamientos rurales que se dieron el momento más álgido del conflicto entre unitarios y federales. Luego del asesinato del gobernador Dorrego en 1828, los pobladores rurales se manifestaron en contra de los unitarios que habían tomado el poder, con Juan Lavalle a la cabeza. Se generó una conflictividad que nació en el ámbito rural y luego se trasladó a la ciudad. ${ }^{12}$ Ante este levantamiento, Rosas emergió como una garantía del orden que lograba aglutinar los intereses de diferentes sectores sociales. Había sido comandante de milicias rurales y contaba con el apoyo de sectores populares, además pertenecía al universo de la campaña por estar entre los propietarios de tierras más importantes de la Provincia. Su retorno al gobierno para el segundo y extendido mandato se dio en 1835. Nuevamente en un contexto de enfrentamientos entre diferentes sectores, esta vez del propio federalismo. Una vez finalizado el conflicto que tuvo como corolario la

\footnotetext{
${ }^{11}$ Elegimos referirnos a notables y no a élites ya que, como ya ha trabajado la bibliografía no siempre son lo mismo y sus límites pueden ser confusos. Notables, para el período entre fines del siglo XVIII y mediados del siglo XIX, nos ilumina sobre aquellos personajes que participaron de los diferentes escalafones de los elencos locales de poder, tanto político, militar, económico, eclesiástico y judicial. De este modo, un notable de un pueblo de campaña no necesariamente era rico, pero sí probablemente contaba con una densidad de vínculos producto de sus actividades múltiples (Banzato, 2012; Gelman, 2000).

${ }^{12}$ Recuperamos aquí la bibliografía que ha trabajado este contexto de conflictividad rural. Una de las conclusiones principales a las que estos autores han llegado es que los alzamientos, montoneras y levantamientos sucedieron de manera más o menos autónoma y no dirigidos por el propio Rosas (Di Meglio, 2013; Fradkin, 2008; González Bernaldo de Quirós, 1987).
} 
Germinario. La crisis como oportunidad. Una aproximación a partir del Levantamiento de los Libres del Sur...

marginación de los federales no rosistas de la política porteña, comenzó un período de aparente tranquilidad y prosperidad en la Provincia.

La Ley Fundamental de 1825 y luego el Pacto Federal de $1831^{13}$ habían establecido que Buenos Aires tenía las atribuciones de relaciones exteriores, paz y guerra. Por este motivo, el comienzo de la guerra contra la Confederación Peruano-boliviana en 1837 fue impulsada por Rosas, quien designó al tucumano Alejandro Heredia como encargado de la conducción. La guerra impactó fuertemente en las provincias del norte, que debieron soportarla financiera y humanamente. Heredia fue asesinado en 1838, mientras que la guerra finalizó en 1839. Si bien Buenos Aires sólo participó a través del envío de armamento y apoyo económico (Kloster, 2019), esta contienda fue el preludio de conflictos regionales ${ }^{14}$ que tendrían alto impacto en la estabilidad de la política bonaerense ya que implicó una situación de guerra que potenció la aparición de disidencias. ${ }^{15}$ Por ejemplo, en muchas de las provincias del interior se exacerbaron las tensiones políticas y el disgusto para con Rosas. En 1840, Tucumán, Salta, Jujuy y Catamarca formaron una liga o Coalición del Norte, que bajo el lema "Libertad, Constitución o Muerte", demandaban la reunión de un Congreso Constituyente. La solución de Rosas fue una violenta represión que para 1842 cerró toda posibilidad de diálogo con las provincias al imponer a sus aliados.

\footnotetext{
${ }^{13}$ La Ley Fundamental fue promulgada por el Congreso Constituyente convocado en 1824. La ley establecía, entre otras cosas, que se reconocían las instituciones provinciales hasta que se dictara una Constitución, y que provisoriamente se delegaba el ejecutivo en Buenos Aires. El Pacto Federal de 1831 fue firmado en primera instancia por Santa Fe, Buenos Aires y Entre Ríos, luego se adhirió Corrientes. El Pacto fue una alianza político militar a la que las demás provincias fueron uniéndose a medida que adherían a la forma de gobierno federal. Uno de los aspectos más importantes del Pacto fue la creación de una comisión representativa, que funcionaba como organismo provisorio, formada por un representante por provincia que prepararía la reunión de un Congreso Nacional.

${ }^{14} \mathrm{Al}$ referirnos al espacio sudamericano evitamos, al menos para la primera mitad del siglo XIX, utilizar referencias a los límites propios de los Estado-Nación consolidados efectivamente hacia las postrimerías del siglo. Adherimos a la propuesta de una perspectiva regional que "pretende a romper con los moldes interpretativos estatal-nacionalistas que siguen primando a la hora de abordar territorialmente el fenómeno de las guerras rioplatenses" (Etchechury Barrera, 2017, p. 26).

${ }^{15}$ Elegimos este vocablo en función de haberlo encontrado en las fuentes utilizadas:

Rosas sigue hablando de la Confederación Argentina; y para eso la tal Confederación se reduce a solo Santa Fe y Entre Ríos. Todas las demás provincias están contra él; pues Córdoba, que era lo que no se había decidido todavía acaba de entrar a la liga, que han formado contra el tirano. Aun la de Santa Fe parece que empieza a conmoverse; pues acabamos de saber que un Comandante ha levantado el grito en Coronda con ciento y cincuenta hombres, y que ha arrebatado las caballadas de López. Sabemos también que todas las Provincias disidentes van a hacer una declaración solemne de que no reconocerán ningún convenio que celebre Rosas con las Naciones Extranjeras. (El Grito Argentino n. ${ }^{\circ} 1,24$ de febrero de 1839)
}

A su vez, en diccionarios del siglo XIX también identificamos una acepción similar a la actual de disidente: "el que se sustrae de la obediencia debida a las potestades legítimas", "el que en una corporación se separa del modo de pensar del mayor número". (Salvá, Vicente (1847) Nuevo diccionario de la lengua castellana. Que comprende la última edición integra, muy rectificada y mejorada, del publicado por la Academia Española, y unas veinte y seis mil voces, acepciones, frases y locuciones, entre ellas muchas americanas, añadidas por Don Vicente Salvá. París: librería de Don Vicente Salvá. Segunda Edición. p.409) Por lo tanto, la categoría la utilizamos en su sentido histórico y también analítico. 
El año 1838 fue la fecha bisagra que inició una crisis muy profunda, de la cual Rosas salió victorioso, pero también significó la introducción de muchos cambios en los mecanismos de sostenimiento de su poder. En este año comenzó el bloqueo del puerto de Buenos Aires por parte de una escuadra naval francesa comandada por el Almirante Leblanc. El motivo que impulsó esta medida radicaba en la disputa de poder de carácter global entre Francia e Inglaterra, y la voluntad de la primera de lograr una presencia económica relevante en el Río de la Plata, tal como ya tenían los británicos (Etchechury Barrera, 2014, p. 61). La justificación coyuntural fue la protección de ciudadanos franceses en Buenos Aires que se habían visto vulnerados. Otro conflicto regional que tuvo impacto en la ciudad porteña fue el cambio de gobierno en la reciente creada República Oriental del Uruguay ${ }^{16}$. La otra orilla del Río de la Plata fue el destino elegido por muchos disidentes porteños. Fructuoso Rivera y Manuel Oribe fueron los dos líderes que, por estos años, se enfrentaron por el poder en Uruguay, alternando entre la simpatía, la desconfianza y el enfrentamiento con el gobernador de Buenos Aires. En este escenario, la presencia de emigrados en Montevideo, sumada al bloqueo, complejizó la política local y regional, generando una dinámica entre ambos estados que nos permite abonar a un enfoque que deje de lado las fronteras de los Estados-Nación posteriores. En un primer momento, en 1836, Rivera, con la compañía del General Lavalle y otros emigrados, generó una rebelión contra Oribe, que fue contenida a los pocos meses. En este escenario, Oribe y Rosas se aliaron circunstancialmente (Beverina, 1922, pp. 122-123). Hacia fines de 1837, Rivera nuevamente intentó tomar el poder, esta vez con éxito, desplazando a Oribe en octubre de 1838. Oribe pasó entonces al territorio de la Confederación, siendo auxiliado por las fuerzas federales y reconocido por Rosas como "Presidente Legal de la República Oriental en el exilio". En 1840, Oribe cumplió un rol fundamental en la defensa de la zona norte y la derrota del Ejército Libertador liderado por Lavalle. En octubre de ese año fue nombrado por Rosas como general en jefe del Ejército de Vanguardia de la Confederación, lo cual le dio la autoridad para conducir los triunfos de las fuerzas federales frente a la Coalición del Norte (Miralles Bianconi, 2017). Una vez controlada la situación en la Confederación, en 1842, Oribe regresó a la República Oriental para dar inicio al sitio de Montevideo y recuperar así el poder (Halperín Donghi, 2010, p. 361).

Entonces, pasamos ahora a desentrañar los problemas que había en el interior de la Provincia. Destacamos dos conjuntos de problemas: uno de índole económico/ financiero causado, principalmente, por el bloqueo y otro, político/disidente. Éste último tiene que ver con que el escenario de desafíos externos habilita los cuestionamientos al gobierno de Rosas y posteriores intentos de desplazarlo del poder. Ambos tipos de conflictos están vinculados, aunque aquí nos interesa profundizar en la acción política de los actores. Para los fines explicativos, dividimos el análisis de los grupos de problemas. Sin embargo, sostenemos que las dificultades económicas y las prácticas de los actores

\footnotetext{
${ }^{16}$ La República Oriental del Uruguay fue establecida en 1828 como parte de los acuerdos posteriores al fin de la Guerra entre las Provincias Unidas del Río de la Plata y el Imperio del Brasil. La región que comprendía era conocida previamente como Provincia Cisplatina, un área que desde tiempos imperiales suponía conflictos y tensiones entre la Monarquía Hispánica y el Imperio Portugués.
} 
Germinario. La crisis como oportunidad. Una aproximación a partir del Levantamiento de los Libres del Sur...

deben entenderse de manera integral. El Levantamiento de los Libres del Sur configuró alineamientos disidentes que se explican a partir de lo económico y de lo político, sin privilegiar uno $\mathrm{u}$ otro aspecto.

\section{La economía de Buenos Aires: "las finanzas de la guerra permanente"}

Las dificultades económicas y financieras fueron una constante del período. $\mathrm{Si}$ bien Buenos Aires contaba indudablemente con recursos más abultados que el resto de las provincias, también tuvo que hacer frente a graves problemas de este tipo. El mayor gasto que afectó a las economías provinciales fue el militar. Las guerras recurrentes requerían de la manutención de los ejércitos con todo lo que ello implica: armamentos, salarios, vestimenta y alimento, entre otros. En el caso particular de la Provincia de Buenos Aires durante el segundo mandato de Rosas, Halperín Donghi señala que, además del gasto militar, comenzó a haber un desequilibrio en el gasto público, causado por la deuda. La solución del gobernador fue apostar a la austeridad en los gastos: "los de educación, sanidad y asistencia social son simplemente borrados del presupuesto (...). Más efectiva a largo plazo es la congelación del nivel de remuneraciones nominales para la entera administración civil, militar, eclesiástica, policial..." (Halperín Donghi, 2005, p. 194). Sin embargo, estas medidas no lograron contrarrestar los efectos que produjo el crecimiento en el gasto militar, inevitable dada la conjunción de conflictos regionales e internos a la provincia suscitados hacia 1838. Una vez superada la crisis, Rosas salió fortalecido, por lo que Halperín Donghi sostiene que durante estos años el gobierno bonaerense logró construir un nuevo orden administrativo, una "fórmula para las finanzas de la guerra permanente", lo cual le permitió encarar con éxito los años siguientes (Halperín Donghi, 2005, p. 167).

Desde una perspectiva socio-económica, hubo dos conjuntos de medidas fiscales que tuvieron un impacto destacado en el ámbito rural bonaerense: los cambios introducidos en la política de tierras y las modificaciones impositivas. En cuanto a la primera, se establecieron modificaciones a la enfiteusis ${ }^{17}$. En primer lugar, en 1836 se decidió la venta de 4.050 .000 hectáreas bajo este régimen. Para ello, se dispusieron los siguientes precios: 5000 pesos la legua, al interior del Salado; 4000 pesos, desde dicho Río hasta una línea que pasaba por el Volcán, Tandil, Laguna Blanca, fuertes Mayo y Federación; fuera de esta línea, 3000 pesos (D’Agostino, 2012, p. 105). En segundo lugar, a partir de 1837, se ordenó la duplicación del canon de enfiteusis y la renovación de los contratos que vencían en ese año. Por último, se decretó la venta de tierras de titulares que no hubiesen cumplido con el pago correspondiente. Entre 1836 y 1843 fueron escrituradas 3.411.042 hectáreas de tierras públicas, lo que representaba el $50 \%$ de las tierras en enfiteusis. El mayor número de operaciones se produjo a partir de 1838. Desde ese año y hasta 1843 se vendieron algo más de 2.363 .500 hectáreas, beneficiándose en su mayoría los propios enfiteutas (93\%), aunque también compraron

\footnotetext{
${ }^{17}$ El sistema de enfiteusis, dispuesto en 1822, implicaba la prohibición de la venta de tierras por parte del Estado Provincial y sólo se permitía la cesión, a través de arrendamientos de largo plazo con el pago de un canon.
} 
tierras los arrendatarios (D’Agostino, 2012, p. 106). La otra medida fue la modificación de la Contribución Directa (CD). En 1839, el gobierno de Rosas modificó la ley, al integrar las tierras públicas en enfiteusis al impuesto y al poner en manos de las autoridades de cada partido la tarea de evaluar los bienes a gravar. De este modo, hubo un aumento significativo en la cantidad de capitalistas censados y en la recaudación efectuada. En parte, porque los responsables de contabilizar percibían el 1\% de lo recaudado (Gelman \& Santilli, 2004, p. 241).

Estas medidas tuvieron un desarrollo diferencial en el sudeste de la campaña, sobre todo, en función de las características económicas y socio-demográficas que presentamos antes. El partido de Monsalvo fue uno de los que registró mayor cantidad de operaciones de escritura de enfiteusis en el periodo, con 405.348 hectáreas, correspondientes al 51,7\% del total de las tierras bajo este sistema en la sección. En Dolores, durante la década de 1830, 213.818 hectáreas en enfiteusis pasaron al dominio de particulares, lo que equivalía a, aproximadamente, el $81,5 \%$ de las tierras en este régimen (Mascioli, 2004, p. 158). Los cambios en la CD también tuvieron un impacto muy importante en los partidos del sur. Mientras que en 1837 los partidos de Dolores, Monsalvo y Tandil tenían 77, 88 y 22 capitalistas censados respectivamente, en 1839, se registraron 262 en Monsalvo, 205 en Dolores y 193 en Tandil. El aumento pudo tener varios factores, entre ellos la nueva forma de controlar y de medir el impuesto, pero lo que resulta muy significativo es que este crecimiento en la cantidad de capitalistas, que casi se triplica en los partidos de sur, no es tan evidente en otras secciones del norte o del oeste (Gelman, 2009, pp. 80-81).

Como consecuencia de la estructura económica y social de la campaña sur de Buenos Aires, el impacto del bloqueo al puerto de Buenos Aires por naves francesas parecería, en una primera instancia, un golpe muy duro para todos aquellos habitantes que se dedicaban a la exportación de derivados ganaderos entre sus principales tareas. Sin embargo, como ha mostrado Antonio Galarza, esta situación podría matizarse si se tiene en cuenta, por ejemplo, el uso, como puerto alternativo, que se le dio a la desembocadura del Río Salado. El autor muestra cómo el uso, desde años previos, de este puerto permitió en esta, y en otras coyunturas de crisis, que los pobladores de la zona se adaptaran a las críticas coyunturas. Por otra parte, esta entrada y salida de mercancías alternativa se hacía más difícil de ser controlada por las autoridades (Galarza, 2014, p. 104). En este sentido, en las fuentes consultadas identificamos también el intento de uso de otro puerto alternativo en 1840, el de la Lobería en el partido de Mar Chiquita. En un intercambio entre el Juez de Paz y Rosas, el primero le comunica que "en una carreta de Don José Mancilla se remiten ocho cajones, pertenecientes al estado, desembarcados en la Lobería"18. A su vez, en una de las comunicaciones, el comandante en jefe del Regimiento número 5 de campaña, Narciso del Valle, le escribe a Rosas: "el infrascripto adjunta a la carta la nota que ha recibido del Sr. Juez de Paz de la Mar Chiquita Don Manuel Saavedra con el objeto que ella expresa los cargamentos de particulares que

18 "Dolores, agosto 25 de 1840. El Juez de Paz de Dolores Al Excelentísimo Señor Gobernador y Capital General de la Provincia Ilustre Restaurador de Nuestras Leyes Brigadier Don Juan Manuel de Rosas." Archivo General de la Nación (en adelante AGN), X, 21.1.2. 
Germinario. La crisis como oportunidad. Una aproximación a partir del Levantamiento de los Libres del Sur...

existen en tierra en la costa de la Lobería para que en vista de ella se diga resolver lo que fuera de su superior agrado". ${ }^{19}$

Al tener en cuenta estos elementos y hacerlos dialogar con lo expresado previamente es que se hace necesario articular la crítica coyuntura económica con una crisis política. La acción destacada de muchos propietarios ricos del sudeste de la campaña no necesariamente significa que las medidas económicas sean la causa directa de su participación en el Levantamiento. Por este motivo, es necesario integrar estas modificaciones a la enfiteusis y a la CD con los aspectos de calibre político. La propuesta es no reducir el Levantamiento al accionar político de los sectores más acaudalados que se habrían visto afectados y que lograron convencer al resto de los pobladores de la región. De esta manera, buscamos discutir la explicación que desde el rosismo se realizó de la sublevación. En ésta se adjudicaba a unos pocos cabecillas la responsabilidad, mientras que, el resto de los participantes fueron perdonados en un primer momento, ya que se consideró que actuaron engañados o forzados.

\section{La crisis como oportunidad: los disidentes entre discursos y armas}

Durante todo el gobierno de Rosas, sus adversarios políticos no dejaron de intentar desestabilizarlo y de manifestar sus desacuerdos. Ya fuera realizando publicaciones en el exilio, organizando logias secretas con fines conspirativos, o hasta tomando las armas. Sin dudas, uno de los actores destacados de esta coyuntura de crisis fue Juan Lavalle; quien había tenido una participación destacada en la crisis del año '28 y, luego de la muerte de Dorrego, había ocupado por un breve período la gobernación de Buenos Aires. Cuando comenzó el bloqueo, Lavalle se encontraba en las filas de Rivera colaborando para el desplazamiento de Oribe, en la República Oriental del Uruguay. Los dos principales sucesos insurrectos al interior de Buenos Aires en 1839, la conspiración de Maza y la sublevación de los Libres, lo tuvieron a él como figura aglutinadora; es un personaje que refuerza la expresión regional del conflicto, si observamos sus acciones posteriores con el Ejército Libertador y la Coalición del Norte.

Para articular las acciones más militares de los opositores a Rosas con las acciones discursivas es necesario contemplar la existencia de las Comisiones Argentinas. Éstas funcionaban como asociaciones de migrantes fuera de la Confederación Argentina, con el objetivo de organizar y ofrecer protección a los contingentes importantes de emigrados políticos que vivían en los países limítrofes (Blumenthal, 2018, p. 146). En su interior convergían miembros de la Generación del '37 con unitarios acérrimos y federales no rosistas que tenían como objetivo derrocar a Rosas, pero también tenían, como trasfondo, ideas románticas sobre la nación y la legitimidad. Sus acciones discurrían entre el plano discursivo propagandístico y las actividades militares y de provisión de recursos, así como también, un intento de representación gubernamental en el exilio (Blumenthal, 2018, p. 147). De este modo, en 1839, la Comisión Argentina en Montevideo tenía

\footnotetext{
19 "Dolores, septiembre 4 de 1840. El Teniente Coronel Comandante en Jefe del Regimiento n5 Al Excelentísimo Señor Gobernador delegado de la Provincia, adjunta una nota del juez de paz de la Mar Chiquita." AGN, X, 21.1.2.
} 
dos tareas centrales: por un lado, entablar diálogos y negociaciones con los franceses para lograr su apoyo a la campaña de Lavalle y, por otro, poner en funcionamiento la lucha política a ambas orillas del Río de la Plata. En una escala más local, al interior de la ciudad de Buenos Aires, los emigrados en Montevideo tenían vínculos con un grupo de antirrosistas porteños que estaban nucleados en el Club de los Cinco. Entre los miembros de estos espacios nuevamente encontramos personajes que no tienen una filiación directa al unitarismo, sino que, por el contrario, muchos de ellos pertenecen a familias de larga trayectoria federal: "estaba compuesto por Enrique Lafuente, un funcionario de la Secretaría de Rosas; Santiago Albarracín —quien financiaba los gastos del complot—, Carlos Tejedor, Jacinto Rodríguez Peña y Rafael Corvalán —hijo de Manuel Corvalán, edecán de Rosas" (Zubizarreta, 2015, p. 31). Este grupo, junto con otros actores, fue el artífice de la Conspiración de Maza. La vinculación que tenían las acciones desempeñadas por estos grupos, a ambas orillas del Río de la Plata, era tal que Lavalle pasó a convertirse en una especie de jefe de Estado en el exilio: "buscó contactos con los antirrosistas de Buenos Aires para un desembarco sorpresivo, y trató de ganar el mayor número de jefes militares en actividad que se plegarían. El enlace de la Comisión y Lavalle con Buenos Aires lo hacían los jóvenes Félix Frías y Avelino Balcarce" (Rosa, 1962, p. 401).

El complot tenía como objetivo allanar el camino para el desembarco de Lavalle en Buenos Aires, con ayuda francesa y con acciones en la ciudad y en la campaña. Por intermedio de José Lavalle, hermano del anterior, lograron la adhesión de Ramón Maza, un teniente que ocupaba el segundo lugar en el Regimiento de Dolores, cuyo padre era el presidente de la Legislatura porteña. La imprudencia de los conspiradores y la efectividad de las redes de apoyo de Rosas le permitieron, en junio de 1839, descubrir el complot y tomar medidas. Tanto Ramón como su padre Manuel Maza fueron asesinados. El primero, fusilado por orden del Gobernador y, el segundo, por miembros de La Mazorca, brazo armado de la Sociedad Popular Restauradora.

De acuerdo con Pedro Lacasa, sobreviviente de los Libres, escritor y biógrafo de Lavalle, éste se vio muy conmovido por la noticia. A partir de este momento comenzó a organizarse para realizar una avanzada efectiva sobre el territorio de la Confederación Argentina. ${ }^{20}$ Previo al desenlace violento de la conspiración, ya habían estado en contacto con Pedro Castelli, ${ }^{21}$ por intermedio de Marcelino Martínez Castro, quien estaba interesado en sumarse a la sublevación contra Rosas desde el sur de la campaña, donde gestionaba una estancia. Este enlace es el comienzo de los Libres del Sur, quienes, a pesar del descubrimiento de la conjura citadina, decidieron seguir adelante con sus planes a la espera del avance de Lavalle.

Entonces, si bien Juan Lavalle cumplía la función de articulador de los movimientos sediciosos, encontramos que, hacia fines de agosto de 1839, según relata

\footnotetext{
${ }^{20}$ Lacasa, P. (1858). Vida militar y política del general argentino Don Juan Lavalle. Buenos Aires: Imprenta Americana. pp. 64-65.

${ }^{21}$ Según Lacasa, Castelli y Lavalle habían sido compañeros de armas. Lacasa, P. (1858). Vida militar y política del general argentino Don Juan Lavalle. Buenos Aires: Imprenta Americana. p.63.
} 
Germinario. La crisis como oportunidad. Una aproximación a partir del Levantamiento de los Libres del Sur...

Ángel Carranza ${ }^{22}$, Marcelino Martinez Castro recibió una carta, por intermedio de Jacinto Rodríguez Peña, en la que Lavalle le informaba su decisión de no avanzar sobre Buenos Aires, sino sobre Entre Ríos. La decisión de Lavalle estaba fundamentada en que el gobernador de Entre Ríos, Pascual, Echagüe había avanzado hacia el territorio oriental, siguiendo órdenes de Rosas, con el fin de desestabilizar a Rivera. Por lo tanto, a criterio de Lavalle, Entre Ríos se encontraba desprovista de tropas que pudieran hacerle frente. A su vez, la situación entre Rivera y Lavalle, aliados en un principio, se había vuelto tensa por la decisión del líder oriental de evitar una guerra abierta contra Rosas. En una carta que Lavalle le escribe a Andrés Lamas, ${ }^{23}$ ya desde la isla Martín García, le dice que:

Todos los argentinos que quieren embarcarse son presos, y los que van de aquí a buscar víveres, lo son igualmente. Siento no tener aquí ahora una de estas órdenes, para Vd. se lamentase del horrible espíritu con que están concebidas. Querido, yo nada espero del general Rivera sino hostilidades; está poseído de una rabia frenética no tanto contra la empresa, cuanto contra mí. ${ }^{24}$

Tan solo unos días después, el 10 de agosto de 1839, cuando Echagüe ya había pasado a la República Oriental del Uruguay al mando de fuerzas federales, Lavalle le escribe nuevamente a Lamas:

Todo ha cambiado de aspecto desde que el ejército enemigo el Uruguay en el Salto, y desde que encuentro cooperación en el gobierno oriental y simpatía en el pueblo. No perderé el tiempo en demostrar Vd. que el ataque sobre la provincia de Buenos Aires era vicioso considerado política y militarmente. Era un efecto de las fatalidades que Vd. conoce: yo no tenía otro

\footnotetext{
${ }_{22}$ Ángel Justiniano Carranza fue uno de los miembros fundadores de la Junta de Historia y Numismática Americana (1893). Ocupó múltiples cargos en la función pública vinculados a su condición de abogado. Escribió varios trabajos que podrían ser considerados dentro del género reivindicatorio de personajes históricos, como por ejemplo de Juan Lavalle. Su obra La revolución del 39 en el sud de Buenos Aires (1880) recupera los testimonios de contemporáneos y documentación escrita, con la que Carranza "aspiraba a recuperar la memoria del episodio sin aspiraciones literarias ni de partido, pero alentadas por la búsqueda de la verdad sin querer avivar resentimientos" (Devoto \& Pagano, 2009, p. 55). Su producción se inserta en un contexto histórico e historiográfico que, a pesar de la pretensión de objetividad, se paraba en un lugar de valoración binaria hacia el pasado, catalogando a Rosas como tirano y a Lavalle, como el Libertador. Por este motivo, la obra es recuperada en nuestro trabajo por el valioso valor documental y testimonial, producto en parte, de los vínculos personales que el autor tenía con los involucrados y sus familias.

${ }^{23}$ Andrés Lamas era auditor de Guerra de la República Oriental del Uruguay y por este motivo era el enlace entre Lavalle y el gobierno oriental. Además, fue un escritor prolífico en prensa de la época y es considerado un pionero de la disciplina histórica en Uruguay, ya que fue el fundador del Instituto Histórico y Geográfico del Uruguay.

${ }^{24}$ Martín García, 18 de julio de 1839. El General Lavalle al Señor don Andrés Lamas, Montevideo, citada en Carranza, Á. (1919). La revolución del 39 en el sud de Buenos Aires. Buenos Aires: Casa Vaccaro p. 76.
} 
camino. Pero después que el Estado Oriental ha sido invadido, ese ataque no sería una falta sino un crimen. La revolución argentina ha de ser completa para que produzca todo el bien que desean los pueblos. Rosas y Echagüe deben caer. A mí me es indiferente empezar por una o por otra parte, pero no al pueblo oriental invadido. Yo tengo pues que obedecer a su interés que es el interés de todos: el de nuestra hermosa causa. Querido, me voy a Entre Ríos: en Buenos Aires se van a desesperar, pero así lo exige el bien público ${ }^{25}$

De este modo, el Levantamiento de los Libres del Sur siguió por su propio curso, ajeno a las decisiones del líder político. Cómo veremos, aún mantenían la retórica y los vínculos ya establecidos ya que, una vez derrotada la sublevación, muchos de los cabecillas que huyeron se sumaron a las filas de Lavalle en su campaña hacia el norte. Pero esta situación nos permite vislumbrar que, así como el Levantamiento no puede explicarse por separado de la coyuntura de crisis política, militar y económica de alcance regional, tampoco podemos obviar los aspectos particulares locales del sud de la campaña. Pasaremos ahora a comentar porqué nos resulta novedoso integrar estas explicaciones.

\section{La crisis económica y política en la campaña. Una explicación integral}

La participación de personajes con importancia económica de la campaña en el Levantamiento es indudable. Gelman ha mostrado que, entre los líderes, sesenta y ocho estaban incluidos en los censos realizados para el cobro de la Contribución Directa, luego de la modificación de 1839 (Gelman, 2009, p. 73). Pero, a su vez, la reforma que el rosismo realiza del impuesto incluye, a partir de 1839, a capitalistas no tan acaudalados, conformando un segmento heterogéneo. El propio autor señala también que, para comprender las causas de la rebelión se debe tener en cuenta las cuestiones políticas y culturales. En esta misma línea, Galarza sostiene que, para poder "mensurar el peso y la forma en que el factor económico incidió en el levantamiento", es necesario abordar el entramado político local y las relaciones entre los comerciales, que es el conjunto que analiza, y otros actores (Galarza, 2010, p. 42). Gelman se enfoca en cómo, desde el gobierno de Rosas, a través de la movilización de los sectores populares, se había ido, progresivamente, categorizando a la "gente decente" como sospechosa de unitarios (Gelman, 2009, p. 82). Mientras que Galarza agrega que es probable que "el enriquecimiento que la actividad comercial permitía pudo haber influido en la asociación de los comerciantes más acaudalados con la figura de cagetillas y unitarios, en contraposición a los llamados hijos del país, asociados al estandarte federal" (Galarza, 2010, p. 42). El descontento de éstos, que tiene en los aspectos económicos una de sus explicaciones, se entrelaza también con quiénes eran estos personajes, a qué familias

\footnotetext{
${ }^{25}$ Martín García, 10 de agosto de 1839. El General Lavalle al Señor don Andrés Lamas, citada en Carranza, Á. (1919). La revolución del 39 en el sud de Buenos Aires. Buenos Aires: Casa Vaccaro p. 83.
} 
Germinario. La crisis como oportunidad. Una aproximación a partir del Levantamiento de los Libres del Sur...

pertenecían, cuáles eran sus actividades en el entorno local y cuáles eran sus redes de relaciones. Estos aspectos los reconstruimos en otro trabajo y exceden a los fines de este artículo. Del análisis realizado, encontramos que los líderes del Levantamiento ${ }^{26}$ componían un conjunto heterogéneo, integrado por militares de larga experiencia, miembros de familias destacadas desde tiempos virreinales, integrantes de los elencos de juzgados de paz y de las milicias de la campaña, reconocidos federales, entre otros. A su vez, muchos de ellos eran propietarios, enfiteutas o ejercían algún tipo de explotación rural o comercial en la zona. Una de las conclusiones parciales a las que arribamos es que se encontraban, en su gran mayoría, fuertemente insertos en redes de relaciones familiares, comerciales, de vecindad y de amistad que tenían un anclaje territorial. Es decir que las características referidas del espacio geográfico del sudeste de la campaña tuvieron un rol importante en la configuración de estas redes y en la circulación de estos actores en este ámbito, que facilitó la organización de la sublevación, como veremos más adelante.

Entonces, si integramos los problemas económicos, las decisiones fiscales y los aspectos relaciones y políticos, podemos decir que el ámbito de la campaña era propicio para una rebelión. Entre las dificultades causadas por el bloqueo y los enrolamientos forzosos, la desazón con respecto a Rosas era moneda corriente. Sin embargo, más allá de las dificultades, el foco de las críticas era justamente la forma en la que el gobierno manejaba la crisis y las decisiones que tomaba para aminorarla (Gelman, 2009, p. 78). Nos centramos ahora en un análisis de las fuentes que nos permitan mostrar cómo lo económico y lo político formaban parte del discurso antirrosista que circulaba, tanto en el ámbito regional, como en el local que estudiamos.

La presencia de periódicos antirrosistas en la campaña, que incitaban a un movimiento sedicioso, era advertida por los aliados del Gobernador. ${ }^{27} \mathrm{El}$ periódico $\mathrm{El}$ Grito Argentino era editado en Montevideo y tenía como objetivo principal llegar a aquellas personas que no estaban enteradas de quién era verdaderamente Rosas, como dice en el primer número publicado el 24 de febrero de 1839: "No hablamos con los hombres que están enterados de las cosas: sino solamente con la Campaña, y con aquella parte de la Ciudad, que no sabe bien quien es Rosas, porque solo ve la embustera Gaceta Mercantil". ${ }^{28}$ Diego Jarak analiza los recursos literarios que utiliza el periódico para cumplir su objetivo, como por ejemplo un lenguaje llano e imágenes, con el fin de llegar a un público no letrado (Jarak, 2014). Esta publicación comenzó a realizarse en febrero de 1839 y se discontinuó en junio del mismo año, en conjunción con el descubrimiento de la Conspiración de Maza. En total, se emitieron treinta y tres números. ${ }^{29}$ Encontramos

\footnotetext{
${ }^{26}$ Hasta el momento logramos reconstruir las trayectorias parciales de alrededor de 20 sujetos.

${ }^{27}$ Jorge Gelman cita una carta que Nicolás Anchorena le envía al Gobernador en junio de 1839. En ella, Anchorena le anexa unos ejemplares del diario El Grito Argentino que le habían arrojado a sus mayordomos en una de sus estancias (Gelman, 2009, p. 55).

${ }^{28}$ El Grito Argentino ${ }^{\circ} 1,24$ de febrero de 1839.

${ }^{29}$ Todos los ejemplares se encuentran conservados en la Hemeroteca de la Biblioteca Nacional Mariano Moreno (CABA) y digitalizados para su consulta libre en el sitio web de la institución.
} 
en el trabajo de Ángel Carranza, un comentario muy locuaz al estado de ánimo que imperaba en el sud de la Provincia y a la presencia del periódico El Grito Argentino:

En esa época, el espíritu de la campaña del Sud se hallaba en la mejor disposición para secundar cualquiera tentativa armada contra el sistema de terror que imperaba. De ello estaban persuadidos los misteriosos agitadores de la insurrección, puesto que habían explorado aquel sentimiento de antemano y lo alimentaban con tenaz perseverancia.

Obedecían a esta combinación, hasta los pasatiempos congeniales a nuestros hombres de campo, entre los que descollaban las carreras y las boleadas, reuniones que a pesar de su crecido número no podían despertar la suspicacia infatigable de la autoridad. (...)

Los colores verde y celeste proscritos en la ciudad, se ostentaron indistintamente por todas partes y el Grito Argentino periódico ilustrado que aparecía en Montevideo contra Rosas, no sólo era leído y comentado por los gauchos en las pulperías, en los alegres fogones de las cocinas y en los corrales que son su escuela favorita, sino que circulaba también por las carretas en que sus familias concurrían a esas fiestas agrestes, penetrando hasta en las carpas de los oficiales de milicias, convertidas ya en foco de discusión política ${ }^{30}$

Cada número del periódico tenía una extensión de cuatro hojas. En la última siempre se presentaba una caricatura. En la argumentación presentada, se puede ver la voluntad, por parte de quienes escribían, de atraer a los pequeños campesinos y labradores de la campaña. La familia Anchorena ${ }^{31}$ era uno de los focos de las críticas presentes en el diario:

No son tan brutos los paisanos como tu crees, Juan Manuel. Todos saben que tú, y los avarientos Anchorenas, solo tienen la culpa del bloqueo, y de la miseria del país; y que cayendo tu, los franceses serán nuestros amigos; y no habrá bloqueo; y valdrán más los frutos de la campaña, y habrá trabajo y abundancia de todo: y no habrá auxilios de reses y caballos, ni el robo de derechos dobles de marca. Manda no más que prediquen lo que quieras; burlate de la religión; y sigue entalegando onzas de oro con tus primos Anchorenas; roba, roba junto con ellos; que pronto pagaras tus maldades. ${ }^{32}$

\footnotetext{
${ }^{30}$ Carranza, Á. (1919). La revolución del 39 en el sud de Buenos Aires. Buenos Aires: Casa Vaccaro, p. 31

${ }^{31}$ Los Anchorena, emparentada con el Gobernador Rosas, se encontraban entre las familias más acaudaladas del período (Banzato, Infesta, \& Valencia, 2018, pp. 151-153).

${ }^{32}$ El Grito Argentino no12, 7 de abril de 1839.
} 
Germinario. La crisis como oportunidad. Una aproximación a partir del Levantamiento de los Libres del Sur...

La referencia al valor de los "frutos de la campaña" era recurrente en el diario:

...después que entró a gobernar ese bárbaro que se titula Restaurador, padre de los pobres, y amigo de los paisanos ¿dónde está la riqueza y la felicidad de la campaña? La ha destruido con su tiranía y sus locuras. Hoy el ganado se vende a razón de un peso plata: la legua del mejor campo sale apenas cuatro mil pesos de un papel desacreditado que casi no tiene valor alguno: ni los estancieros tienen a quien vender sus novillos, ni los peones encuentran donde ocuparse, ni en que ganar su vida ni la de sus familias. Entretanto van a comprar una arroba de yerba, una vara de tabaco, un poncho, una chiripa, y todo cuesta un sentido; porque todo lo que el país produce ha bajado considerablemente de precio, y todo lo que viene de afuera ha subido. ${ }^{33}$

La voluntad de quienes escriben, de mostrar cómo la crisis económica afecta a todos por igual, estancieros y peones, es significativa. En este fragmento se hace referencia también al valor para las ventas de las tierras en enfiteusis, que como vimos antes estaba diferenciado según la zona de la campaña. Es destacable que cuatro mil pesos era el precio de las tierras al sur del Salado, foco de la posterior sublevación. Con respecto a la enfiteusis, encontramos varios comentarios: "Labradores! Ya veis lo que es Rosas. ¡Él debe todo a la campaña! ¿Y cómo la trata? A los hacendados los ha secado con auxilios, donativos y hasta contribuciones de marcas; y a los que tienen tierras en enfiteusis, y no pueden, o no les hace cuenta el comprarlas, las arroja de ellas". ${ }^{34}$

En esta selección vemos también que el sujeto a quien se dirigen son los labradores, diferenciándolos de los hacendados. El bloqueo, los enfrentamientos con las otras provincias y con la Confederación Peruano-Boliviana, la violencia ejercida por la Mazorca, eran algunos de los tópicos comunes del diario. Según mencionan en algunos números, en las diferentes ediciones integraban noticias y escritos provenientes de emisarios. Nos es interesante destacar un fragmento de un comunicado que, según los editores de El Grito, recibieron de la campaña:

Tomás Rocha, de 62 años de edad, que había sido sargento en la guerra de la independencia, y que subió de soldado al Perú en 1812, vivia retirado en su casa, cerca del Quequén. Ahora tres años que se le obligó a engancharse por dos años. Sirvió bien en el Tandil: pero como concluidos los dos años, no se le diese su baja, y fuesen inútiles sus repetidos ruegos y representaciones, desertó: fue aprendido quince días después; y en el acto se le cortó la cabeza que fue envuelta en muchos trapos y enviada a Rosas con un teniente alcalde, diciéndole

\footnotetext{
${ }^{33}$ El Grito Argentino n ${ }^{\circ} 14,14$ de abril de 1839.
}

${ }^{34}$ El Grito Argentino n ${ }^{\circ}$, 7 de marzo de 1839. 
que era unitario. Regresado aquí el teniente alcalde, refiere que el gobernador, aunque examinó mucho la cabeza desaprobó el hecho. Esto ha sucedido en marzo. ${ }^{35}$

Al margen de la veracidad o de las opiniones de Rosas sobre este hecho puntual, sí es importante destacar el peso que las levas tenían para los pobladores de la campaña. Este tópico es frecuente en el diario, en un número anterior señala que:

se impusieron contribuciones con el nombre de empréstito voluntario, ya de dinero, ya de ganados y caballos: se llenaron las cárceles y cuarteles de los hombres más pacíficos y honrados de la ciudad y la campaña: se autorizó y premió el más vil espionaje: se destinó a las armas a muchos vecinos, padres de numerosa familia y trabajadores; fusilándolos, si no asistían a una lista, o si desertaban, por no pagarles, para buscar con que dar de comer a sus hijos. ${ }^{36}$

No podemos tomar como verdad todo lo que El Grito Argentino sostiene, ya que era una plataforma política y propagandística de un grupo que tenía como interés principal desestabilizar a Rosas. Pero, como vimos, la presencia del periódico en la campaña era un hecho. Por lo tanto, sí interesa destacar la difusión de estas ideas insurrectas para hacernos una imagen aproximada de cuál era el clima político durante el tiempo previo a la sublevación. Mientras tanto, Rosas intentaba controlar la situación sosteniéndose en sus hombres fieles. Por ese motivo, luego de la conspiración de los Maza, envió a Dolores al comandante Vicente González, a cargo del Regimiento de Campaña $n^{\circ} 3$ con sede en Chascomús, a visitar el pueblo. Este hecho está documentado en un informe que el Juez de Paz de Dolores envía a Rosas notificando la visita con fecha 23 de junio de 1839. En el informe, el Juez relata todas las celebraciones (misas, desfiles, comidas, bailes, canto del himno) que se hicieron en honor de la visita de González y su comitiva. Hace hincapié en las prácticas "federales" y en el orden, respeto y obediencia que imperan en el partido ${ }^{37}$. De este informe podemos inferir algunas cuestiones. En primer lugar, es evidente que había un clima de inestabilidad e incertidumbre, ya que se deja entrever en el informe que la visita había sido avisada con muy poca antelación. En segundo lugar, hay un intento muy locuaz del Juez de Paz por demostrar que en el partido de Dolores hay alegría y obediencia a la causa federal. Al respecto de esto, Jorge Gelman, que utiliza como fuente la correspondencia entre González y Rosas, muestra que el Coronel refiere que se lo recibió con vítores y fiestas. También destaca que "al paso de un personaje poderoso, cuya fidelidad a Rosas era incuestionable, se manifiesta públicamente adhesión al régimen, aunque cuatro meses después el mismo lugar sea el centro del levantamiento de los Libres del Sur" (Gelman, 2009, p. 55).

\footnotetext{
${ }^{35}$ El Grito Argentino $\mathrm{n}^{\circ} 20,5$ de mayo de 1839.

${ }^{36}$ El Grito Argentino $\mathrm{n}^{\circ} 16,21$ de abril de 1839.

${ }^{37}$ El informe se encuentra en el legajo del Juzgado de Paz de Dolores. "El Juez de Paz de Dolores a Juan Manuel de Rosas, Dolores, junio 23 de 1839. Da cuenta de la visita que ha hecho a este pueblo el benemérito Coronel Don Vicente González y su comitiva", AGN, X, 21.1.2.
} 
Germinario. La crisis como oportunidad. Una aproximación a partir del Levantamiento de los Libres del Sur...

\section{La puesta en marcha del Levantamiento}

El Levantamiento de los Libres del Sur se hizo público el 29 de octubre en Dolores. Marcelino Martínez Castro fue el enlace entre el Club de los Cinco y la campaña. Según Carranza, luego de entrevistarse con Juan Bautista Peña y Ramón Maza, Martínez Castro, se dispuso a contactar a quienes creía que se sumarían a organizarse contra Rosas en el sur:

Dos días después llegaba a la estancia de Chacabuco, encontrando la mejor disposición en su propietario don Francisco Ramos Mejía, quien tomó a su cargo verse personalmente con su amigo don Benito Miguens en las Cinco Lomas de Lara, anticipando su entera adhesión (...) fue indispensable verse con éste [Matías Ramos Mejía] en Marihuincul, y su actitud decidida confirmó en todas mis partes el pensamiento de su hermano, puesto que añadió, que no sólo su persona, sino también su familia, sus intereses y cuanto podía valer lo consagraba a la idea de salvar la patria de las garras del opresor. Martínez, acompañado siempre por el joven Ezequiel Ramos Mejía, pasó luego al cerro de Paulino con el objeto de iniciar a Castelli, y entregarle una carta de Lavalle. Éste alegó su incompetencia para encabezar cualquier movimiento; pero estrechado por aquél en una larga conferencia, concluyó por ser convencido, jurando reunir a sus parciales para incorporarse con ellos. ${ }^{38}$

Como ya comentamos arriba, el desenlace fatal de Maza impulsó a Lavalle para comenzar a organizar su avance sobre el territorio de la Confederación. Se desplazó a la isla Martín García, que estaba ocupada por tropas francesas, y permaneció allí durante dos meses. ${ }^{39}$ Durante su estancia en la isla, Lavalle se reunió y mantuvo correspondencia con emisarios de los diferentes grupos antirrosistas, tanto en Buenos Aires como en Montevideo. A fines de julio de 1839, Marcelino Martínez Castro, por intermedio de Jacinto Rodríguez Peña, le hizo saber a Lavalle que, en la campaña sur, estaba todo listo para su llegada y que lo esperaban con todo lo disponible en el puerto de la Laguna de los Padres, donde tenía su estancia:

Este [Marcelino Martínez], después de prevenir que las señales de inteligencia serían dos fogatas al pie del cerro más próximo a la ensenada de la Laguna de los Padres, salía de Buenos Aires en pleno invierno y bajo un copioso aguacero en la madrugada del 29 de julio, uniéndosele en los Tapiales de Ramos Mejía el joven don Francisco B. Madero. Consecuente con su plan,

\footnotetext{
${ }^{38}$ Carranza, Á. (1919). La revolución del 39 en el sud de Buenos Aires. Buenos Aires: Casa Vaccaro p. 28.

${ }^{39}$ Lacasa, P. (1858). Vida militar y politica del general argentino Don Juan Lavalle. Buenos Aires: Imprenta Americana. pp. 66.
} 


\section{apenas perdía de vista los suburbios de la ciudad, ya fue preparando el terreno para que germinaran las nuevas ideas.} Ferrari en la costa del Samborombón, Gándara en la de Vitel, Lastra en las Lagunas, los Ramos Mejía en Kakel, Miguens en las Cinco Lomas, Castelli en el Cerro de Paulino y demás enemigos de Rosas, fueron enterados de que Lavalle se hallaba en Martín García al frente de una columna de patriotas resueltos y en vísperas de lanzarse sobre las costas del sur protegido por los buques franceses (...) Según se ha dicho en diverso lugar, Don Marcelino Martínez estaba a cargo de ese valioso establecimiento [Laguna de los Padres, Sierra del Volcán] en 1839, y así que regresó a él, contando con la secreta amistad del señor Otamendi, Juez de Paz de Monsalvo, que se hallaba en la Ballenera. ${ }^{40}$

A través de esta descripción del movimiento, desde la ciudad hacia la campaña, realizado por Martínez Castro podemos inferir algunos elementos. En primer lugar, cómo la organización del Levantamiento se presenta totalmente rural, desde las ideas hasta los recursos. Esta descripción de Carranza presenta un uso político del espacio, que permite discutir la asociación de la campaña como el bastión del federalismo rosista (Fradkin \& Gelman, 2015, p. 384). Esta idea fue uno de los tópicos recurrentes del romanticismo rioplatense, que entendía a lo rural como la barbarie y la tradición, en contraposición de la ciudad como la civilización. ${ }^{41}$ En segundo lugar, la decisión estratégica de establecer contacto con personajes que estuviesen establecidos en accesos marítimos o fluviales. ${ }^{42}$ En tercer lugar, aparecen aquí los nombres

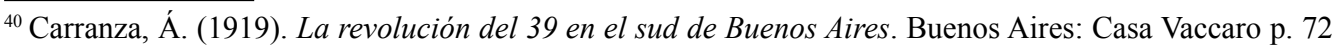
Las negritas son nuestras.

${ }^{41}$ Estas ideas fueron clave en la producción escrita de Domingo Sarmiento y Esteban Echeverría, dos de los más importantes exponentes de este movimiento, que se encontraban exiliados y eran opositores a Rosas.

${ }^{42}$ Lacasa realiza en su obra una descripción de estos lugares. Su objetivo es, en parte, explicar por qué Lavalle decidió no desembarcar en esta zona, pero más allá de eso, evoca características geográficas del espacio de la campaña sur que resultan explicativas de la propia percepción de los actores participantes de su experticia: La "Boca del Salado" es un buen puerto; habría sido fácil desembarcar allí. ¿Pero sería fácil también tomar caballos? Los que no conocen la localidad y los inconvenientes, que entonces existían, responderán que sí: nosotros con un conocimiento exacto del terreno, en posesión de todas las circunstancias, que en esa época hacían imposible un desembarco allí, sostenemos lo contrario. La Boca del Salado está situada en la parte culminante del triángulo, que forma el territorio conocido por el nombre de "Rincón de Nuario"; de ese punto a la villa de Chascomús, hay 15 leguas de distancia, y en toda esta área de terreno, que es la que se conoce por este nombre, entre los Ríos de "Samborombón" y "Salado," no había en esos tiempos pobladas más estancias, que las de los Sres. Pinero, Escribano, y Miguens, enemigos los tres de la administración de Rosas. Al Sud del mismo puerto está situada la hacienda conocida por la denominación de "Rincón de López”, perteneciente a D. Gervasio Rosas. En esa localidad había establecida una gran guardia del tirano para vigilar el puerto, (...) si el General Lavalle se hubiera dirigido con su expedición a la "Boca del Salado," dado caso que hubiera podido desembarcar, se habría encontrado completamente a pie. En la rada del "Tuyúu" 
Germinario. La crisis como oportunidad. Una aproximación a partir del Levantamiento de los Libres del Sur...

de algunos de los cabecillas: Ramos Mejía, Madero, Ferrari, de la Gándara, Lastra, Miguens, Castelli y Otamendi (figura 2).

Figura 2. Ubicacón aproximada de los sitios utilizados por los rebeldes

1- Pueblo de Dolores
2- Laguna de los Padres
3- Costa de Samborombón
4- Laguna de Vitel
5- Caquel
6- Laguna de Lastra
7- Cinco Lomas de Lara
8- Cerro de Paulino
9- Los Tapiales de Ramos Mejla
10-EStancia el Duranzo de Ereiza
11- Estancia Espuela Verde de
Piedrabuena
12-Estancia La Postrera de Cramer
13-Pueblo de Chascomús
14-Estancia Bella Vista de Álzaga
- Ciudad de Buenos Aires

Fuente: Elaboración propia sobre la Carta Geográfica de 1829 (AHGyC), el Reistro Gráfico de 1830 (AHGyC y Mascioli (2004))

Otra referencia que ilustra la relevancia explicativa del espacio geográfico para la organización de la sublevación es una carta de autor desconocido. El 15 de octubre de 1839 el Juez de Paz de Dolores, Manuel Sánchez, remitió a Rosas una carta fechada el 12 de septiembre en Monsalvo, firmada por J.R.A. y destinada a Don Justo B. Martínez. En la misiva el autor pone al corriente de los preparativos de un movimiento en favor de la "Causa de la Libertad". Se desconoce quiénes son el remitente y el destinatario, y supuestamente fue entregada al Juez de Paz por un ciudadano que la encontró en la calle, y Sánchez, temiendo que fuese una maniobra de Rosas para probar su adhesión a la causa federal, la envió al Gobernador (Iriarte, 1971, p. 82) . La carta comienza comentando que "acabo de llegar recién de las Loberías, después de 11 días, que sin cesar he recorrido casi toda la campaña del Sud. Hoy hice de pasada una visita a la casa que tenemos destinada para nuestra reunión; y felizmente encontré allí a Pancho que también estaba de regreso de su Comisión. Me es muy satisfactorio a V. que tanto a Pancho como a mí nos ha ido muy bien a los demás compañeros los esperamos mañana a más tardar". ${ }^{43}$

\footnotetext{
la prudencia aconsejaba no pensar. (...) El "Cabo de Corrientes", o sea, el puerto de la "Laguna de los Padres", dista cien leguas de Buenos Aires en los mares del Sud, y es completamente desamparado por todas partes. Lacasa, P. (1858). Vida militar y política del general argentino Don Juan Lavalle. Buenos Aires: Imprenta Americana. Pp. 67-68. El resaltado es nuestro.
}

${ }^{43}$ Una copia de la carta, realizada por el Juez de Paz de Dolores Manuel Sánchez, se encuentra preservada en el AGN, Sala X, Secretaría de Rosas, 26.6.5. El original, según dice, fue remitido al Gobernador. La 
De este fragmento podemos analizar algunas cuestiones. La carta se encuentra fechada en el 12 de septiembre, por lo tanto, hacía ya más de un mes de la llegada de Martínez Castro a la zona. Quien escribe estuvo durante once días (es decir, desde comienzos de septiembre) recorriendo "casi toda la campaña del Sud". Resulta llamativo que haya podido realizar esto sin sufrir consecuencias de los hombres leales a Rosas. Por lo tanto, podemos inferir que quien escribe no era sospechoso porque tenía una movilidad recurrente por la zona o porque conocía muy bien por qué caminos desplazarse para no encontrarse con partidarios rosistas. De cualquier modo, es probable que era alguien cuya presencia en la campaña del sur no sólo no era extraña, sino que probablemente era donde se esperaba verlo. Por otra parte, cuando se refiere a "la casa que tenemos destinada para nuestra reunión" sólo podemos suponer, de acuerdo con Carranza, la Estancia "El Durazno" de Ezeiza, ubicada en la Mar Chiquita y la estancia "Espuela Verde" de Leonardo Piedrabuena, fueron los lugares utilizados para las reuniones de los sublevados. Quizás es allí donde se encontró el autor anónimo con "Pancho", quien puede ser Francisco B. Madero o Francisco Ramos Mejía.

La carta continua así:

La caballada que para el caso tenemos lista ya pasa de 300, y permanece en las Estancias con la debida reserva a fin que nadie sepa para que son. Todo presenta por acá el más agradable aspecto a la causa de la Libertad. Casi ningún trabajo me ha costado el persuadir a más de 200 gauchos a abandonar al Tirano, pues ellos de su motivo en varias conversaciones conmigo, me han manifestado el odio que le tienen y lo dispuestos que están a seguirnos, con tal que sea para echarlo abajo

Este fragmento ilumina la cantidad de personas que se estaba proyectando para participar en el levantamiento. Por supuesto que, al no saber quién es el autor de la carta, se pueden poner en duda muchas de sus afirmaciones, y aunque lo supiéramos también ya que podría verse como una "propaganda" política. Pero el levantamiento efectivamente sucedió $\mathrm{y}$, de acuerdo con diferentes fuentes, contó con miles de combatientes por el bando rebelde. ${ }^{44}$

Si nos enfocamos nuevamente en quién es el personaje que escribe, parece claro que es alguien cuya presencia, entre los pobladores de la campaña, es atendida. Por lo

carta tiene como encabezado ¡Viva la Libertad! Monsalvo, septiembre 12 de 1839, Señor Don Justo B. Martínez.

${ }^{44}$ Una vez derrotado el Levantamiento, Prudencio Rosas eleva al Gobernador una nota en la que dice que "tenían reunidos como mil trescientos milicianos a la fuerza". Archivo Histórico de la Provincia de Buenos Aires, La Gaceta Mercantil. Buenos Aires 1823-1852. Volumen VIII (1838-1839). Buenos Aires Provincia. Edición digital. 9 de noviembre de 1839. En cuanto al número de detenidos, en la misma carta Prudencio Rosas sostiene que hubo alrededor de 250 muertos y 200 detenidos, pero en otras comunicaciones posteriores Nicolás Granada dice que serían 450 muertos y otros 500 prisioneros (Gelman, 2010, p. 65). 
Germinario. La crisis como oportunidad. Una aproximación a partir del Levantamiento de los Libres del Sur...

tanto, es probable que fuese de renombre, con autoridad y considerado notable por el paisanaje. Resulta también destacable que el personaje hace uso de la persuasión y del diálogo, buscando comprender las problemáticas que aquejan a los pobladores de la campaña. Esta podría ser una forma de diferenciarse de las prácticas de reclutamiento del gobernador que, como vimos antes, era una de las críticas frecuentes en la prensa opositora. La carta continúa comentando que, según los gauchos, Rosas los tiene "pobres y jodidos con el bloqueo" y que, desde Dolores. le comentan que todo por ese pueblo está listo, incluso los paisanos estuvieron haciendo proclamas del Libertador (Lavalle). Más adelante, refiere que no hace falta que les envíen más armas, ya que es muy peligroso porque los conductores, aunque se les pague muy bien, "no son de fiar".

Luego, dice lo siguiente: "El número de patriotas decididos y aliados a Nuestro Libertador que tenemos seguros en Dolores (fuera de los que usted conoce) asciende ya a 48, todos estos son vecinos de la zona, y con el espantajo de los bigotes, luto, cintillo y cintas pasan por muy federales". Al margen de la cantidad de vecinos decididos a participar, resulta ilustrativa la mención a los símbolos característicos del rosismo asociados inevitablemente con el federalismo. La contrapartida de esta imagen eran los unitarios, que no usaban bigote, ni patillas ni cintillo punzó (Dominguez Arribas, 2003, p. 561). Matizamos en este trabajo el binomio unitario-federal, y proponemos que también los federales no rosistas podían verse molestos por el uso de estos símbolos. Suponer que el rechazo a estos elementos convertía a una persona o un grupo en adherente a los unitarios sería tomar por válido el discurso oficial de Rosas y desconocer los matices internos del federalismo, cuestiones que aún no han sido estudiadas en profundidad para el segundo mandato. Después, en la carta se menciona a Narciso del Valle y a Sánchez, diciendo que "el día menos pensado van a tener el Juez de Paz y el tiranuelo Valle, que anda por acá tiranizando". Por último, el autor anónimo se compromete a comunicarse cuando lleguen los demás compañeros y le aclara que en otra carta que le envió usó una clave: "al leer esa otra carta que le remito, tenga presente que la clave es el abecedario al revés, cambiada la $\mathrm{Z}$ por la A, la Y por B".

La aparición de la misiva se sumó a una serie de rumores relativos a posibles conspiraciones en el sud de los que Rosas ya estaba sobre aviso (Gelman, 2009, p. 57). En uno de los intercambios entre el Edecán Manuel Corbalán y el jefe del Regimiento n. ${ }^{5}$, Narciso del Valle, Corbalán le escribe: "A S.E. nada de este le sorprende en cuanto ve que en su desesperación no les queda otro recurso que la lengua, ni otras armas que la intriga para hacer lo que ellos llaman guerra al Gobernador (...) V.S. sabe que estos no dejarían de ejecutar sus pensamientos (...) no los pierda de vistas y los seguirá muy de cerca para escarmentarlos". ${ }^{45}$

Entonces, si bien Rosas y sus hombres más leales estaban al tanto de la posibilidad de una conspiración, no lograron frenarla a tiempo. Inferimos que la participación de personajes que, hasta ese mismo momento, eran considerados federales fieles fue una de las razones que permitió la concreción del Levantamiento. Otra razón, y la que

\footnotetext{
${ }^{45}$ El General Edecan de S.E. Manuel Corbalán al Comandante en Jefe del n ${ }^{\circ} 5$ Coronel Don Narciso del Valle, Buenos Aires, 20 de octubre de 1839. AGN, X, 26-6-5.
} 
intentamos mostrar aquí, tiene ver con la inserción de estos actores en sus entornos locales y en relación con esto, el conocimiento que tenían del espacio geográfico que les permitió concretar la sublevación.

En síntesis, desde el año 1838 imperaba un clima de crisis caracterizado por la inestabilidad política y económica que ponía en cuestión el poder del Gobernador. Los intentos de conspiraciones dan cuenta de la complejidad de la sociedad rioplatense, tanto urbana como rural, y demuestran que es necesario superar el análisis dicotómico entre unitarios y federales y entre urbano y rural. Los propios antirrosistas sostenían: "Por más que Rosas grite, como le duele, la verdad es que ya se acabaron los partidos; que ya hoy nadie usa de corazón las palabras federales y unitarios, con las cuales él supo engañar, para tiranizar a unos y a otros". ${ }^{46}$

Y, en las palabras de Castelli, líder del levantamiento: "ya no existen los bandos sangrientos que nos despedazaron". ${ }^{47}$ La crisis se cerró hacia el año 1841, una vez finalizado el bloqueo en 1840 y contenidos los intentos de las provincias del interior de enfrentarse a Rosas. En la campaña, también hasta el año 41 veremos el impacto que tuvo el Levantamiento en la cuestión territorial y jurídico-administrativa.

\section{Conclusiones}

A lo largo del trabajo hemos tratado de mostrar cómo el levantamiento de los Libres del Sur fue una sublevación que no puede explicarse únicamente por los problemas económicos del período. La rebelión respondió a un abanico de situaciones que necesariamente debemos abordar de manera multicausal. El impacto del bloqueo del puerto, las decisiones de orden impositivo y fiscal de la gobernación fueron algunos de los elementos, que se entienden mejor cuando observamos cuáles eran las particularidades de la campaña del sur. Y, como ya cierta bibliografía ha propuesto, para comprender las motivaciones de los actores de involucrarse en el levantamiento, las respuestas vinculadas a sus prácticas socio-económicas son insuficientes. En este esquema, resulta iluminador comprender la sublevación, en el marco de la coyuntura de crisis y la oportunidad vislumbrada por los opositores, a Rosas. La figura de Lavalle, sus acciones y sus decisiones tuvieron un rol central en el devenir de los acontecimientos, pero también nos muestran que el levantamiento tenía vida propia más allá del líder. Es así como la carta anónima y la reconstrucción realizada por Carranza, en diálogo con El Grito Argentino exhiben las complejidades de la campaña sur. Si sumamos, además, que quienes lideraron la sublevación componían un grupo heterogéneo, tanto en sus prácticas económicas, como políticas y familiares, pero que tenían en común, su alto grado de inserción en la campaña, comprendemos también la importancia de las redes de relaciones situadas en el espacio.

\footnotetext{
${ }^{46}$ El Grito Argentino ${ }^{\circ} 1,24$ de febrero de 1839.

${ }^{47}$ Fragmento de la proclama de Pedro Castelli que circuló por la campaña durante el Levantamiento de los Libres del Sur. Extraída de Carranza, Á. (1919). La revolución del 39 en el sud de Buenos Aires. Buenos Aires: Casa Vaccaro, pp.187-188.
} 
Germinario. La crisis como oportunidad. Una aproximación a partir del Levantamiento de los Libres del Sur...

El levantamiento de los Libres del Sur duró muy poco y fue duramente derrotado. Muchos de los que lograron salir con vida se sumaron a las filas de Lavalle y otros pasaron al exilio forzosamente. ${ }^{48}$ Pero su impacto perduró en la campaña largamente. En primer lugar, a través de las divisiones territoriales del sudeste realizadas hacia fines de 1839, que buscaron romper con la espacialidad que hizo posible la sublevación y superponer nuevas redes de relaciones fieles al gobernador. En segundo lugar, los embargos de bienes a sospechados de unitarios, realizados durante el año 1840 fueron un golpe para muchos habitantes de la campaña que habían superado el levantamiento sin ser castigados. La conflictividad en el ámbito rural se desplazó hacia la zona norte con el avance de Lavalle y su ejército, aunque allí fue mucho más clara la adhesión a Rosas. De allí en más, el curso de aquellos que decían defender la libertad tomó rumbo hacia el norte de la Confederación. Excede a los fines de este trabajo cuales fueron los devenires de aquella empresa, aunque si podemos decir que es necesaria una articulación de las diferentes escalas para comprender cómo, en tiempos de enfrentamientos abiertos, el poder adquiere una dimensión territorial que es puesta en juego y discutida por los actores de acuerdo con sus intereses y prácticas.

\section{Fuentes documentales}

El General Edecan de S.E. Manuel Corbalán al Comandante en Jefe del $n^{\circ} 5$ Coronel Don Narciso del Valle, Buenos Aires, 20 de octubre de 1839. Archivo General de la Nación, Departamento de documentos escritos, Sala X, Secretaría de Rosas, legajo 26-6-5.

¡Viva la Libertad! Señor Don Justo B. Martínez, Monsalvo, 20 de septiembre de 1839, copia del Juez de Paz de Dolores, Archivo General de la Nación, Departamento de documentos escritos, Sala X, Secretaría de Rosas, legajo 26-6-5.

El Juez de Paz de Dolores a Juan Manuel de Rosas, da cuenta de la visita que ha hecho a este pueblo el benemérito Coronel Don Vicente González y su comitiva, Dolores, 23 de junio de 1839, Archivo General de la Nación, Departamento de documentos escritos, Sala X, Juzgados de Paz, legajo 21.1.2 (Juzgado de Paz de Dolores).

Carta Geográfica de la Provincia de Buenos Ayres (1829), Archivo Histórico de Geodesia y Catastro A.H.G. y C. (La Plata), Colecciones: Planos, Mensuras, Mapas, Recopilación documental Departamentos Topográfico y de Ingenieros, Expedientes Antiguos.

\footnotetext{
${ }^{48}$ Algunos de los líderes que lograron sobrevivir y emigrar fueron: Manuel Campos, Valetín Ezeiza, Francisco Villarino y Antonio Pillado. Los cuatro formaron parte de un intento de expedición fallido a las costas de Samborombón que partió desde Montevideo en septiembre de 1840 para llevar armas y recursos para el ejército de Lavalle, relatado por Antonio Somellera, en Somellera, A. (2001) Recuerdos de una víctima de la mazorca 1839-1840, Buenos Aires: Elefante Blanco. 1ra edición: 1962. La obra originalmente fue publicada en una serie de folletines en el diario La Prensa en 1886, bajo el título "La tiranía de Rosas, recuerdos de una víctima de la mazorca".
} 


\section{Prensa}

El Grito Argentino (1839), Hemeroteca de la Biblioteca Nacional Mariano Moreno (C.A.B.A.).

Archivo Histórico de la Provincia de Buenos Aires (La Plata), La Gaceta Mercantil. Buenos Aires 1823-1852. Volumen VIII (1838-1839). Buenos Aires Provincia. Edición digital.

\section{Fuentes éditas}

Carranza, Á. ([1889] 1919). La revolución del 39 en el sud de Buenos Aires. Buenos Aires: Buenos Aires: Casa Vaccaro.

Lacasa, P. (1858). Vida militar y politica del general argentino Don Juan Lavalle. Buenos Aires: Imprenta Americana.

\section{Referencias bibliográficas}

Banzato, G. (2012). El poder de los notables en el espacio local del Río de la Plata entre el siglo XVIII y mediados del XIX. En M. Canedo, Poderes intermedios en la frontera: Buenos Aires, siglos XVIII-XIX, (pp. 249-263). Mar del Plata: EUDEM.

Banzato, G., Infesta, M. E., \& Valencia, M. (2018). "Expansión de la frontera, tierra pública y formación de las elites terratenientes en la provincia de Buenos Aires, 1780-1880”. En M. F. Barcos \& J. Troisi Melean (comps.), Elites rioplatenses del siglo XIX: biografías, representaciones, disidencias y fracasos, (pp.133-167). La Plata: FaHCE, Universidad Nacional de La Plata.

Beverina, J. (1922). "Rosas y Lavalle y la expedición del «segundo ejército libertador»" (1839-1840). Humanidades, 115-130. Recuperado de: https://www.memoria. fahce.unlp.edu.ar/art_revistas/pr.1766/pr.1766.pdf

Blumenthal, E. (2018). "Exilio, guerra y política transnacional. Las comisiones argentinas en la política internacional americana (1839-1845)". Anuario IEHS, 2, 145-167. ISSN-e: 2524-9339.

Ciliberto, M. V., \& Rosas Principi, A. (2014). "Buenos Aires y su campaña inmediata entre fines del siglo XVIII e inicios del siglo XIX: la dinámica productivo mercantil del espacio agrario periurbano en un período de transición". História Revista, 19, 205-235. ISSN-e: 1984-4530.

D’Agostino, V. (2012). Expansión de la frontera y ocupación del nuevo Sur: Los partidos de Arenales y Ayacucho, Provincia de Buenos Aires, 1820-1900. Buenos Aires: Prometeo Libros.

Devoto, F., \& Pagano, N. (2009). Historia de la historiografía argentina. Buenos Aires: Editorial Sudamericana.

Di Meglio, G. (2013). La participación política popular en la provincia de Buenos Aires, 1820-1890. Un ensayo. En R. Fradkin \& G. Di Meglio (eds.), Hacer política: La participación popular en el siglo XIX rioplatense, (pp. 273-303). Buenos Aires, Argentina: Prometeo Libros. 
Germinario. La crisis como oportunidad. Una aproximación a partir del Levantamiento de los Libres del Sur...

Dominguez Arribas, J. (2003). "El enemigo unitario en el discurso rosista (1829-1852)". Anuario de Estudios Americanos, 60, 557-579. ISSN-e: 1988-4273. Recuperado de: https://doi.org/10.3989/aeamer.2003.v60.i2.158.

Etchechury Barrera, M. (2014). "Periferias imaginadas. Guerras facciosas y sueños protectorales en el Río de la Plata (1838-1865)". Prohistoria, 22, 55-79. ISSN: 1514-0032.

Etchechury Barrera, M. (2017). "Aventureros, emigrados y cosmopolitas. Hacia una historia global de las guerras en el Río de la Plata (1836-1852)". PolHis, 20, 20-52. ISSN: $1853-7723$.

Fradkin, R. (2008). ¡Fusilaron a Dorrego! O cómo un alzamiento rural cambió el rumbo de la historia. Buenos Aires: Sudamericana.

Fradkin, R., \& Gelman, J. (2015). Juan Manuel de Rosas: La construcción de un liderazgo político (Primera edición). Buenos Aires: Edhasa.

Galarza, A. (2010). Comercio rural y desigualdad en la campaña sur: Los comerciantes de los pueblos en el levantamiento de los "libres del sud" en 1839. Revista de Estudios Marítimos y Sociales, 3, 31-42. ISSN: 1852-0669.

Galarza, A. (2014). "'Un nuevo puerto para Buenos Aires'. La boca del Río Salado como alternativa a los bloqueos portuarios en el Río de la Plata (1830-1850)". Historia Crítica, 53, 83-107. ISSN: 0121-1617.

Gelman, J. (1996). "Crecimiento agrario y población en la campaña Bonaerense durante la época de Rosas. Tres partidos del sur en 1839". Cuadernos del Instituto Ravignani, 10, 1-32. ISSN: 0524-9767.

Gelman, J. (2000). "Crisis y reconstrucción del orden en la campaña de Buenos Aires. Estado y sociedad en la primera mitad del siglo XIX". Boletín del Instituto de Historia Argentina y Americana «Dr. Emilio Ravignani», 21, 7-31. ISSN: 0524-9767.

Gelman, J. (2009). Rosas bajo fuego: Los franceses, Lavalle y la rebelión de los estancieros. Buenos Aires: Editorial Sudamericana.

Gelman, J. (2010). Rosas estanciero: Gobierno y expansión ganadera. Buenos Aires: Capital Intelectual.

Gelman, J. \& Santilli, D. (2004). Expansión ganadera y diferencias regionales. La campaña de Buenos Aires en 1839. En R. Fradkin \& J. C. Garavaglia (eds.), En busca de un tiempo perdido: La economía de Buenos Aires en el país de la abundancia, 1750-1865, (pp. 235-286). Buenos Aires: Prometeo Libros.

González Bernaldo de Quirós, P. (1987). "El levantamiento de 1829: El imaginario social y sus implicancias políticas en un conflicto rural". Anuario IEHS, 135-176. ISSN-e: 2524-9339.

Halperín Donghi, T. (2005). Guerra y finanzas en los orígenes del estado argentino, 1791-1850. Buenos Aires: Prometeo.

Halperín Donghi, T. (2010). De la revolución de independencia a la Confederación rosita (3. ed., 2. reimpr). Buenos Aires: Paidos.

Iriarte, I. M. (1971). Los Libres del Sur. Todo es Historia, 47, 78-91. ISSN: 2618-4354. Jarak, D. A. (2014). Mitos de creación: Los monstruos del rosismo en la prensa de los salvajes unitarios. Amerika, Recuperado de: https://doi.org/10.4000/amerika.5584 
Jumar, F. (2018). "El mundo hispánico durante el Antiguo Régimen desde los circuitos mercantiles y el espacio económico rioplatense”. Historia Crítica, 23-44. ISSN: 0121-1617.

Kloster, M. (2019). Reflexiones sobre la actividad diplomática de la Confederación de Provincias Argentinas. El caso del Bloqueo Francés (1838-1840). Nuevo mundo mundos nuevos, Recuperado de: https://doi.org/10.4000/nuevomundo.78434

Mascioli, A. R. (2004). Productores y propietarios al sur del Salado (1798-1860). Mar del Plata: Universidad Nacional de Mar del Plata, Grupo de Investigación en Historia Rural Rioplatense.

Miralles Bianconi, M. (2017). "Relaciones entre guerra y política a través del intercambio epistolar durante la campaña militar contra la 'Coalición del Norte' (18381842)", en J. Rodriguez Cordeu (ed.), Actas de las XVI Jornadas Interescuelas/ Departamentos de Historia., (pp.1-17), Mar del Plata: Universidad Nacional de Mar del Plata. Recuperado de: https://interescuelasmardelplata.files.wordpress. com/2017/09/108-miralles-bianconi.pdf

Moutoukias, Z. (2017). Instituciones, redes personales y cambio institucional. Una reflexión a partir de la noción de convención. En M. Bertrand, F. Andújar Castillo, \& T. Glesener (eds.), Gobernar y reformar la monarquía: Los agentes políticos y administrativos en España y América (siglos XVI-XIX), (pp. 95-122). Valencia: Albatros.

Moutoukias, Z. (2018). Instituciones, comercio y globalización arcaica: Una reflexión sobre las redes sociales como objeto y como herramienta a partir del caso rioplatense (siglo XVIII). En A. Ibarra, A. Alcántara López, F. A. Jumar, \& J. M. Imízcoz Beunza (eds.), Actores sociales, redes de negocios y corporaciones en Hispanoamérica, siglos XVII-XIX (Primera edición, (pp. 141-180). Ciudad de México: Bonilla Artigas Editores, Universidad Nacional Autónoma de México, Facultad de Economía.

Palacios, G. (Ed.). (2007). Ensayos sobre la nueva historia política de América Latina: Siglo XIX (1. ${ }^{\mathrm{a}}$ ed.) Ciudad de México: El Colegio de México.

Rosa, J. M. (1962). Historia Argentina. Tomo IV: Unitarios y Federales (1826-1841). Buenos Aires: Oriente.

Santilli, D. (2017). La saga continúa: La historiografía rural de la campaña de Buenos Aires en la primera mitad del siglo XIX. En S. Bandieri \& S. Fernandez (agregar), La Historia Argentina en perspectiva local y regional. Nuevas miradas para viejos problemas, 1, (pp. 279-317). Buenos Aires: Teseo.

Zubizarreta, I. (2015). "Las logias antirrosistas: Análisis sobre dos agrupaciones secretas que intentaron derrocar a Juan Manuel de Rosas, 1835-1840”. Historia Crítica, 19-43.ISSN: 0121-1617. 